
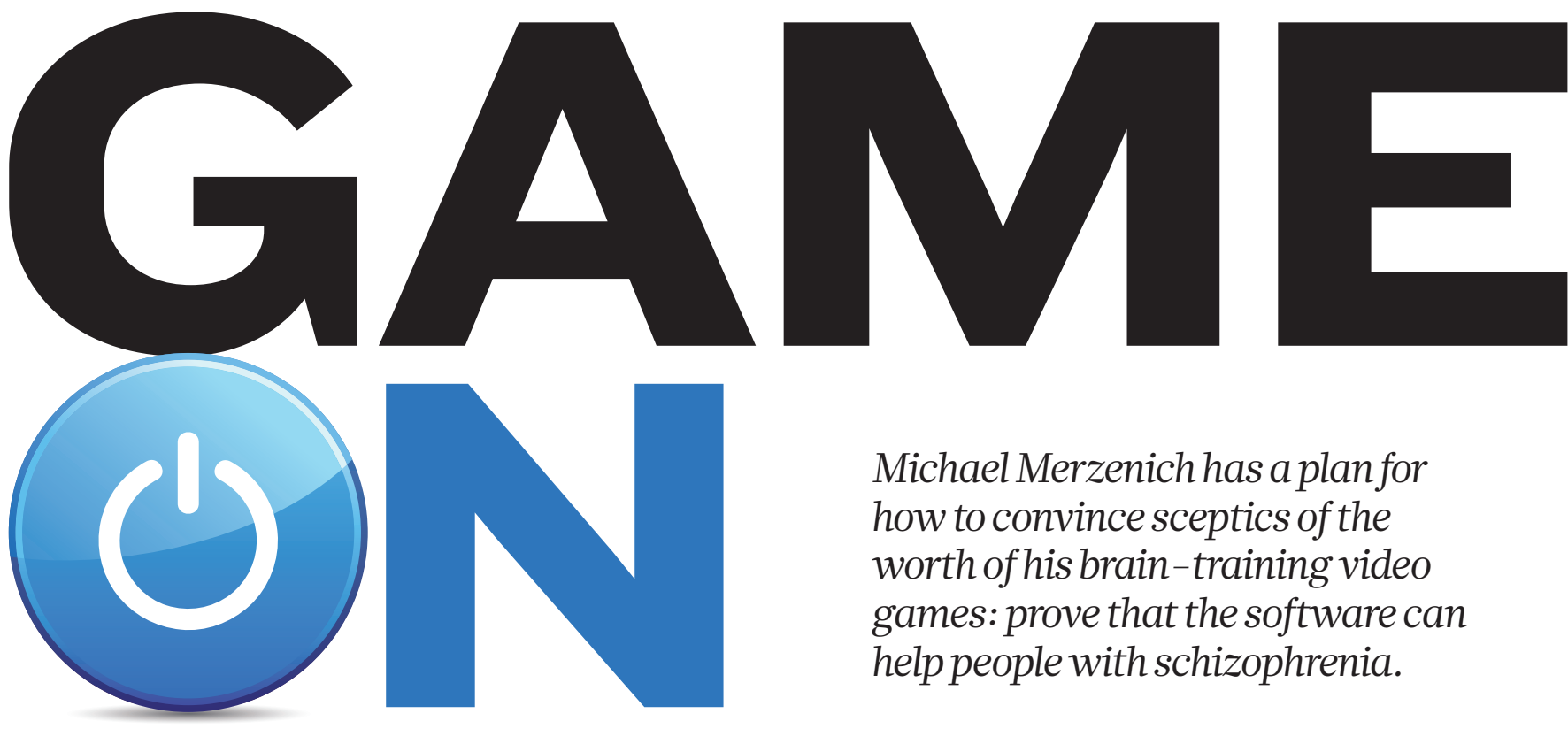

\author{
Michael Merzenich has a plan for \\ how to convince sceptics of the \\ worth of his brain-training video \\ games: prove that the software can \\ help people with schizophrenia.
}

BY ERIKA CHECK HAYDEN

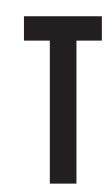

he intersection of Mission and Sixth streets in San Francisco's South of Market neighbourhood is considered one of the most crime-riddled in the city. Liquor shops, adult bookshops and single-resident-occupancy hotels inhabit most of the buildings. Homeless people sit on the pavements or shuffle by, many of them showing symptoms of mental illness or drug abuse. Yet behind the walls of an unassuming outpatient psychiatric clinic, researchers are conducting experiments that they believe could fundamentally change the landscape of psychiatric care.

Inside the San Francisco Citywide and Community Focus Center, in a room about the size of a large walk-in wardrobe, two people wearing headphones sit staring at computer screens. Despite the hubbub - the din of a nearby group session, clients milling in the hallway and the internal turmoil caused by their mental disorders - they are mesmerized by the games on the screens. Both have schizophrenia, and they are taking part in a study that aims to determine whether a controversial method of treatment can succeed where modern medicine has largely failed.

The man behind the games is Michael Merzenich, an emeritus professor at the University of California, San Francisco, and a pioneering advocate for neuroplasticity - the notion that the brain can reshape and remodel its neural pathways even into adulthood. He has gained notoriety for his unabashed promotion of video games designed to tap into that plasticity. These have been marketed to treat everything from reading difficulties in children to driving impairment in elderly people. His zeal has, at times, attracted criticism. There is little solid evidence, say critics, that brain training makes a long-lasting difference in the lives of either ill or healthy people. The languagelearning program Fast ForWord, in particular, has rankled some. "It is a waste of money for schools to pay for these programs that, in my reading of the literature, are ineffective," says Martha Farah, a cognitive neuroscientist at the University of Pennsylvania in Philadelphia.

But this year, Merzenich aims to push the envelope further. He and his colleagues plan to start clinical trials that could lead to a first in the brain-training field: approval from the US Food and Drug Administration (FDA).

FDA approval for the software would give people with schizophrenia a new sanctioned treatment option, and grant legitimacy to Merzenich's work. It will also put pressure on the rest of the brain-training industry to prove the value of its products. Making the case will not be easy. But Murali Doraiswamy, a psychiatrist and neurobiologist at Duke University in Durham, North Carolina, says that Merzenich is fighting an important battle. "If he can present rigorous results on the outcomes that the FDA deems meaningful, it will help everyone else to focus on achieving those goals and weed out the bad players."

Weeding out the 'bad players' is one of Merzenich's main hopes; he has long felt that the field of cognitive training lacks discipline and is happy to share what he thinks of it: "bullshitridden". Even some critics, such as Farah, respect his push for FDA approval. "I think this foray into schizophrenia puts us back in much more familiar territory, where we have systems in place for evaluating whether an intervention is effective."

\section{READY FOR ACTION}

A gruff bear of a man, Merzenich grew up as the son of a farmer in rural Oregon. He owns a small farm in Sonoma County, north of San Francisco, where he makes wine and cures olives, and he arrives for a Monday-morning interview with dirt under his fingernails.

Merzenich earned his $\mathrm{PhD}$ in 1968 at Johns Hopkins University School of Medicine in Baltimore, Maryland, working with Vernon Mountcastle, who laid the basis for brainplasticity studies by showing that the cerebral cortex is organized into vertical columns of neurons that respond to particular stimuli. Merzenich went on to demonstrate in monkeys 
starting to see the disorder as the result of dysfunctions in basic cognitive processes such as attention, learning, memory, speech and problem-solving.

That recognition helped to give rise to a therapeutic approach known as cognitive remediation, which aims to tackle the deficits directly. It also led the US National Institute of Mental Health in Bethesda, Maryland, to commission guidelines for testing interventions in schizophrenia. Called MATRICS (Measurement and Treatment Research to Improve Cognition in Schizophrenia), the guidelines were developed in consultation with the FDA and released in 2005. They spell out which cognitive tests should be used to measure deficits and improvements in seven categories of mental abilities, such as visual learning and problem-solving, and how the tests should be used in clinical trials intended to form the basis of FDA approval. MATRICS was designed to facilitate the development of new drugs, but Merzenich sees it as a road map that could guide trials of braintraining software.

Thanks to the MATRICS guidelines, Merzenich says, "schizophrenia is a relatively simple thing to carry to trial. If you have a significant effect in a clinical population, then you will be given the right to sell the drug." He is optimistic that his treatment will be approved. "I'll tell you right now, we will see benefits in all seven MATRICS categories. We will. Because we already have."

The approach that Merzenich is testing, called Plasticity Assisted Cognitive Remediation (PACR), includes elements from programs that Posit already markets to the general public. One set of exercises focuses on improving the processing of sounds and words through tasks that, for instance, ask the user to discriminate between similar sounds, such as ba and ga, or to decide whether a tone is rising or falling in pitch. Another deploys similar tasks in a visual space - for instance, asking a user to remember where items are hidden, or to spot an object placed in the periphery of his or her visual field. Other exercises, specifically designed for people with schizophrenia, focus on social function.

\section{TRAIN OF THOUGHT}

Sophia Vinogradov, a psychiatrist at the University of California, San Francisco, has already run some clinical trials of Merzenich's software. The goal of treating people with schizophrenia, she says, is to improve fundamental neural processes so that the brain is freed to tackle higher-order cognitive demands such as working memory. By analogy, she says, if you were trying to improve on a lousy tennis serve, you might get better results by focusing on components necessary for the motion, such as balance, coordination and upper-body strength, than by simply repeating your ineffective serve over and over again. People with schizophrenia have
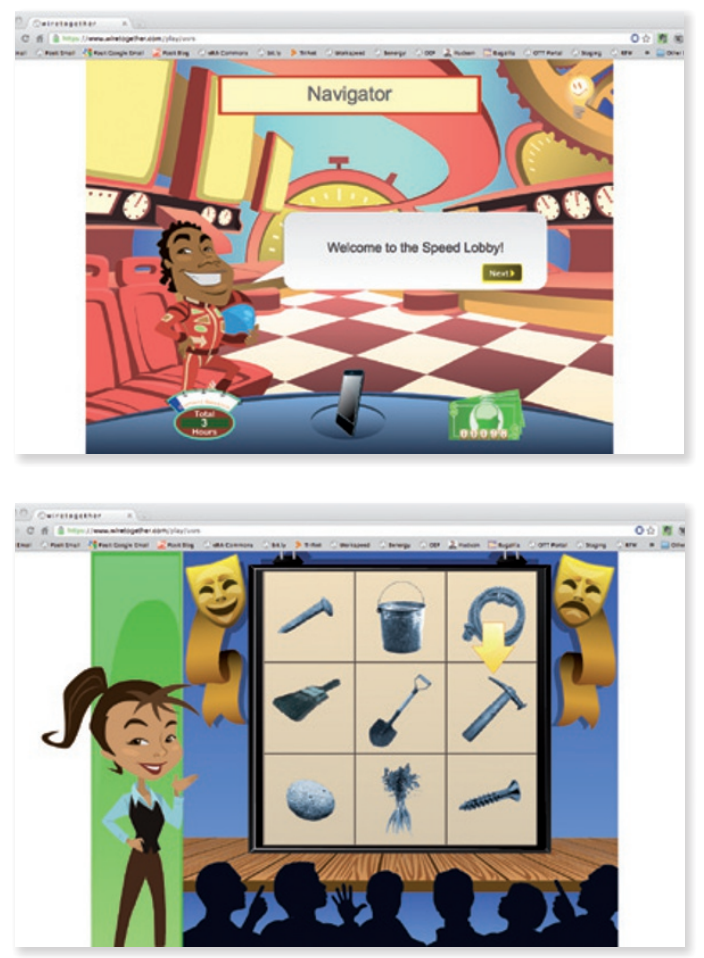

Modules in Merzenich's software for people with schizophrenia target basic cognitive tasks.

problems at multiple levels of auditory and verbal processing pathways, Vinogradov says. "It makes sense to start with early levels of these pathways and work your way up."

Some suspect that Posit will have more success in showing benefits for serious disease than for healthy adults. "If you're very close to maximum performance, you don't have a lot of room for improvement," says Doraiswamy. "Whereas for people in, for instance, a pre-Alzheimer's stage, if you can show $15 \%$ to $20 \%$ improvement, it might mean postponing the development of Alzheimer's by six or eight months."

Vinogradov and others have tested various levels and combinations of these training programs in small groups of people with schizophrenia. She has shown that the most-intensive training tested - 100 hours - can improve global cognition for as long as six months after the training ends ${ }^{5}$. None of the groups showed a significant improvement in symptom severity or quality of life, but Vinogradov speculates that that was probably partly because there were only about ten patients in each group. A small study published last week showed that intensive training can improve people's performance in a task that assesses the ability to distinguish what is real from what is not. Those who improved most had significantly enhanced social functioning six months later ${ }^{6}$.

When combined with other interventions, such as counselling and job-placement programmes, as the current trial at Citywide clinic is, cognitive remediation approaches seem to help patients function better in society - for instance, by helping them to keep jobs ${ }^{7}$. But teasing out what role, if any, the software has in these gains is difficult, partly because the programs have been tested in so many different combinations and conditions.

Alice Medalia, a clinical psychiatrist at Columbia University in New York and a pioneer in cognitive remediation, says that she doesn't think Posit should be seeking FDA approval yet, because it hasn't shown its software to be any better than other cognitive remediation therapies, and because it is not clear how the programs actually treat schizophrenia. A meta-analysis ${ }^{8}$ of cognitive-remediation studies, including those testing Posit's software, found no differences in the effectiveness of various programs - or of other methods of nonpharmaceutical remediation.

This calls into question the scientific rationale of the games, Medalia says. "We have no idea what the active ingredient in these computer-based programs is. Saying that neuroplasticity is the active ingredient is not specific."

Merzenich, however, feels that he has fought long enough to prove the validity of brain training. Now, he says, it is time for regulators to weigh in. Treating schizophrenia with software would mark a change for psychiatry, which tends to focus on dispensing drugs in the first instance. Vinogradov says that the growing realization of drugs' shortcomings and a shift away from the idea that brain deficits are immutable are sparking desire for alternative options.

"The dominant force in psychiatry has been the focus on treating symptoms, not the underlying dysfunction. The patient is this passive object to whom you give pills, as opposed to actively helping to stimulate constructive interaction with his or her environment," Vinogradov says.

And Merzenich doesn't plan to stop with schizophrenia. The Brain Plasticity Institute in San Francisco, another Merzenich-founded company, is studying brain-training software for conditions ranging from Alzheimer's disease to traumatic brain injury. "If we do this in a disciplined way, with scientific confirmation that is beyond question," Merzenich says, "we'll very rapidly evolve into a very important aspect of psychiatric medicine."

Erika Check Hayden is a reporter for Nature based in San Francisco, California.

1. Merzenich, M. M. et al. Neuroscience 8, 33-55 (1983).

2. Mahncke, H. W. et al. Proc. Natl Acad. Sci. USA 103, 12523-12528 (2006)

3. Smith, G. E. et al. J. Am. Geriatr. Soc. 57, 594-603 (2009).

4. Owen, A. M. et al. Nature 465, 775-778 (2010).

5. Fisher, M., Holland, C., Subramaniam, K. \& Vinogradov, S. Schizophr. Bull. 36, 869-879 (2010).

6. Subramaniam, K. et al. Neuron 73, 842-853 (2012)

7. Wexler, B. E. \& Bell, M. D. Schizophr. Bull. 31, 931-941 (2005).

8. Wykes, T., Huddy, V., Cellard, C., McGurk, S. R. \& Czobor, P. Am. J. Psychiatry 168, 472-485 (2011). 